\title{
"Get in, Get out, Go back?" \\ Transitioning from prison ethnography to prison policy research in Russia
}

\author{
Laura Piacentini
}

\section{Introduction}

Prisons are unpredictable worlds that exist in time and in space. They are institutions people 'go to' acting as both a product and a generator of society's lost trust in acts of malevolence, crime and re-offending (Wacquant, 2002). Prisons have endured for centuries and consequently, the arrangement of people, activities and buildings are deeply implicated in a power-knowledge couplet (see Foucault, 1980) where phenomena, events and structures of history are registered and dispersed. Indeed the prison is one of very few institutions where pain, suffering and power are depressed into the entire infrastructure and social fabric. In my ethnographic work a combination of sheer curiosity that Russia remains an uncharted penal territory for Western scholars, coupled with a long-standing personal interest in the region that extended to mastering the language, made the site one of rich and potent allure. What I have learned about all prisons - from doing prison research in Russia - is that 'the place' (jurisdiction) and the 'the site' (the prison) are the repositories of a unique cultural relationship: the relationship between the prison and the state is a clear mirror reflection of the relationship between the person and the state. Thus, the prison reveals the state, which is why prisons are such unique sites of sociological inquiry.

In my chapter I will do two things. First, I will reflect on almost twenty years of doing ethnography in Russian prisons. What I hope to achieve is a better understanding of the totality of the physical, emotional and intellectual challenges of researching a hidden penal system such as Russia's; one which looms large and vast across the European sphere and which weighs heavily in the histories of incarceration in high punishment societies. My own prison research journey is one in which the historical and cultural registers of incarceration can be understood as ruptured, contingent and in a state of cultural to-ing and fro-ing. I now understand my long-term activity in prison research as characterised by moments of both ethnographic mobilization and ethnographic immobilisation of the self in penal space. When I reflect on ethnographic mobilization, I was thrown into a jail environment so chaotic, remote, live, accessible, exciting and unusually welcoming (given its hiddenness from the 
scholarly world) that nothing less than total linguistic, cultural and residential immersion would have worked to complete my research. This is not to claim that mine's is an experience of personal incarceration, but my success in maintaining integrity in the field was measured by my pschyo-social and cultural responsiveness to the 'Rysski mentaliet' (Russian mind-set). The shock and awe of rapid mobilization produced rich data from large scale surveys, qualitative interviews, archival research, oral history analysis and participation in rituals such as collective mourning over incarceration ideals long since gone. Emotions - my emotions played an integral role in the intellectual strategies and research design I employed. I discuss this further on but suffice to say, writing oneself into the lives of (penal) others and not hovering above the penal environment has elicited new insights into how people themselves navigate the vagaries of penal power and how they experience Russia's exceptionally complex penal history today. But whilst the Russian prison system has aged and attempted to become more modernized, it has also suddenly regressed. Its arrested development been accompanied by an intensification in my own intellectual and, if I am frank, emotional commitment ${ }^{1}$ to dig deeper inside this vast penal monolith to hopefully excavate for historical and cultural penal artefacts. When I reflect on ethnographic immobilization, I refer to overt and benign sexism, exploitation, humiliation, observing dire squalor, danger, risky selfplacement and over-immersion in the field. But immobilization of the self in my own prison ethnographic story also refers to my second aim in this chapter which is to ask, as a postscript, how do we interrogate the effects of prison research on the self when the scholarship undertaken moves from field-site to policy-site? What is the place of emotions in policy critique, and where do emotions go? For it must also be said that prisons not only exist in space and time but also exist in policy and law. This begs the question of whether in penal policy scholarship 'emotions' become invisible? Is there a need for emotional safety out of the prison field or is the place of emotion in policy critique the preserve of the penal reform movements? ${ }^{2}$

In the first part of this chapter I offer my own considerations of why we need prison ethnography and its positionality as part of valid social science research design. In the second part I reflect, and bring together, my thoughts on the ethnographic and ethical frameworks

\footnotetext{
${ }^{1}$ The term 'emotional commitment' refers here to personal motivation and how one feels and reacts to the penal degradations of living through cultural, political and psycho-social life in a post-Soviet world that many are still trying to come to terms with.

2 That is, we 'feel' the effects of incarceration when we are presented, through the lens of human rights campaigning or 'persons at risk' campaigns, the horrors of unfair trials, mistreatment of prisoners and human rights abuses in both sentencing and brutalising punishments, torture and arbitrary detention.
} 
that I use in Russian jail research. In the third part I change gear and ask how emotion is measured in policy analysis. That is, when we take the researcher's body out of the culture where prisons are and, therefore, take the body out of prison, what is left and can emotion have a place in critical policy analysis? In my conclusion, I introduce a discussion on the role of the researcher in policy critique and ask questions about the place for emotional narratives, when temporarily transitioning out of the prison field.

\section{We need prison ethnography!}

When referring to methodology, social scientists often debate the best methods for studying social phenomena and, quite often, disagree. The setting and the type of information sought remain the key drivers of the method to be utilized, with some arguing that the best methods are participant observation whilst others will rely on survey methods. Some settings provide particular constraints on researchers due to their configuration, the nature of the study, the subjects who are participating (and their place in society) and the overarching rules governing access to participants. Some forms of information sought are so complex, contentious and troubling that ethical matters can override the pragmatics of capturing everyday life in that particular social milieu. Nowhere is the setting and the type of information sought subject to such scrutiny and reflection than the prison, which since the mid twentieth century, but particularly in the last thirty years, has produced a veritable avalanche of critical sociological insight, reaching wide audiences and creating new 'truths' about human behaviour, order, power, pain, discipline, hope and human relationships. John Irwin's path-breaking classic on prison ethnography shows a principled opposition to quantitative methods:

'any approach not based firmly on qualitative or phenomenological ground is not only a distortion of the phenomenon but is also very likely corruption” (Irwin, 1987: 42).

Irwin goes on to add that it is only through participant observation, guided by theoretical observation, that a researcher is able to reconcile the need for knowledge with the need for objectivity. In addressing these contrary ontological-epistemological tendencies, and the need for balance between being a 'complete participant' or an 'objective outsider' Davis (1973) makes the salient point: 
"For in the end, the capacity to experience the word freshly from the outside and knowingly from the inside is part of the duality of intelligent social life itself. To replicate in our sociological research this duality through an ongoing interior dialogue which constantly counter poses the stark epiphanies of the one to the intimate knowingness of the other..." (Davis, 1973: 342, my underline).

Clearly then, access to 'intimate knowledge' involves letting go of detached objectivity and seeing the group wholly from its members. To paraphrase Rabinow (1988), total immersion in the field changes what we see such that what had been a part has now become a whole, creating a completely new sense of the 'individual' in social settings. The classic prison sociology studies reveal a force of engagement with the field, its captives and custodians (and include Sykes, (1958), Clemmer (1958 ed), Goffman (1958) and Cohen and Taylor (1972)) that we rely upon today because these studies address one of the central issues of our time: what are the social features of penal forms? Moreover, whilst many of these works do not describe their method as explicitly 'ethnographic' common to them all is the sociological significance of being there and a desire to 'know' and 'understand' over and above 'recording' what the research is really about. The focus on prisons' social effects has, until recently, overcrowded prison sociology to the detriment, some argue, of the effects of prison research on the emotions of the researcher despite this being a most fraught and intense environment (see Piacentini, 2004, Jewkes, 2014, Liebling, 2014). As Jewkes (2014) notes:

'there is an unspoken understanding that if we disclose the emotions that underpin and inform our work, our colleagues will question its "validity" and perhaps even our suitability to engage in criminological research' (Jewkes, 2014: 63).

Emotions, therefore, become the competing narrative between what is valid and reliable and what is, simply, 'over-emoting' or as an academic friend once said to me 'go on, have a right good moan!' What the classic sociological studies of the prison from the 1960's onwards had not anticipated was the scale of imprisonment in the late twentieth century and, in particular, the immediate future of US imprisonment. Penal institutions the world over circulate continuously in both public consciousness and the sociological imagination, affecting what we think and feel about the idea of 'the carceral'. As one such member of the prison sociology community, I want to ask questions about the construction of this 'penal commonsense' and its worldwide spread. I want to know how penality coheres with crime, 
but I also want to know the place and purposes of how 'the state', 'culture' and 'community' are represented in penality's unfolding. This is because we are living through a period of deep cultural attachment to confinement in which ideas such as the 'new punitiveness' (Pratt et. al 2005), the 'new penology' (Feeley and Simon, 1992) and the 'culture of control' (Garland 2001) place risk and danger at the centre of a new golden age of hyperincarceration (see Wacquant 2002). Prison scholarship has never been healthier - or more international - because of the seemingly inexorable rise of prison populations in most Western nations but also due to the simple fact that the social response to crime and its control is so pervasive, so complex and so contested. It is in this sense, that we should understand the incredible diversity of prison scholarship against a more sinister backdrop of penal excess. Thus, the embedded practice of carceralism has placed imprisonment centrally in public consciousness and everyday life. Of note, however, is that penal reform has had less of an impact on penal reductionism, which provokes the question as to how, when campaigns for penal reductionism are at their most visible and vocal, our cultural attachment to incarceration is intensifying. That aside, the setting of the prison is generating a profoundly self-reflexive research moment in sociology and criminology. It has been almost twenty years since I began researching the sociology of the prison and I now make sense of the prison as a profoundly cultural world; a world that when I enter I am forced to question traditional modes of prison representation and I have come to understand the penal body politic as a complex and protean one. Yet, when I encounter prisons, anywhere, there is a residual taken for grantedness that goes along the lines of: this is a territory where the contained have become the subject of scientific scrutiny, to be studied in terms of causality. Or what Foucault (1980) refers to as the anatomical gaze where a modern conception of the diseased, the excluded, the-in-need-of-discipline is now constituted as a body subject to regulation and bio-power. Prison, therefore, is centrally about bodies held in regulatory space.

The diverse prison research landscape in front of us has led me and other prison sociologists to reach for new dynamic, epistemological possibilities in better understanding the embodied experience of prison. One development, introduced earlier, can be found in the idea of connecting to the research field through acknowledging the role that emotions, integrity and relational engagement play between researcher and participant. That is mapping the researcher's body on to the territory of prison research, which can produce meaningful and valid methodologies, enhance the data collection and produce substantive gains in the analysis and writing up. Rowe (2014), quoting Hammersely and Atkinson (2007), captures 
the essence of mapping the body on to the prison site well: "the participant researcher is the research instrument par excellence" (Rowe 2014: 404). The ethnographic method - being there, getting close, deep immersion, navigating insider/outside boundaries, connecting to the hidden world and the participants of that world - has produced a polyphony of voices and emotional reactions to the socially complex and impaired world of incarceration. In Forsythe's insightful study of ethnography in technology design research, she argues that ethnography looks and sounds straightforward, that anyone can do it, but as a method, ethnography enables deep perspective and an understanding of what events mean to actors themselves as opposed to what that they would mean if a fieldworker would have done them (Forsythe, 1999). Anthropologists have also expressed strong reservations at do-it-yourself ethnography because it might create superficial social research. Indeed, a trained prison fieldworker will always view ethnography as part of a design process, not a cognitive hall of mirrors. Ethnography helps me to avoid looking at the embodied experiences of incarceration from an (at times) disembodied perspective, or detached position. As others before me have stated, total disembodiment is simply impossible because doing prison ethnography can take the scholar to incredible depths of understandings that go some way in offering new sources of knowledge that do not rely upon a more desk-based approach (see Crewe, 2014a and 2014b). Jewkes (2014) goes further and argues:

I believe that our personalities, histories and emotions penetrate our research in ways that can ultimately enrich our analysis, and give life, vividness and luminosity to our writing' (Jewkes, 2014: 387).

In addition, prisons do not represent 'normal life' but instead take the form of a purified shape whose outline is rejection, confinement and exclusion (Bauman, 2000). Of significance to the ethnographic craft, therefore, is the question of putting the visible self inside a social form of limitless contradiction, pain, and intensity. The prison is where one simply cannot avoid affect on vision, mobility and hearing. Presented in these terms, the researcher's body cannot be ignored but becomes central to alerting us to new ways of understanding how the circuits of power flow, or are disrupted. Hence, if social research requires expertise in writing about emotions - which is not the same as writing emotionally - then ethnographic approaches can assist sociologists to challenge the realist traditions in research methodology and conventional assumptions about imprisoned bodies (see Clifford, 1983 and Coffey, 2000). Turning attention to my own prison scholarship, in the following section, I describe 
the ethnographic experiences of prison research in Russia and I provide new data from diary notes, findings and observations from three studies published in Piacentini, 2004, Piacentini, 2007 and Pallot and Piacentini, 2012.

\section{Transitioning in: Subject, Project, Me?}

Earlier in the chapter I referred to emotional commitment as part of a research design that includes ethnography. Emotional commitment has acted as my own personal benchmark of maintaining integrity and ethics in the field. Echoing Goffman, emotional reactions are entirely normal, indeed necessary, because they involve presenting the self to others (see Goffman, 1958, Jewkes, 2014). It is important to emphasise that emotional commitment is not a methodology in and of itself but instead part of a way of seeing and feeling events, populations and social milieu and placing private thoughts within a cultural and sociological context.

There is an unavoidable cultural repertoire associated with prisons in Russia because current carceral forms and norms contain remnants, or echoes, of wider cultural beliefs about 'being Russian' that provide for an intense common sense coherence (see Smith, 2008). Kharkhordin (1999), mapping out the theoretical territory of what it means to be an individual in contemporary Russian society, makes the salient point that in the post-Soviet period 'collectivism', the professed hallmark of Marxist/Leninist life, has given way to an outpouring of internal, previously-privatized desires and emotions that are non-linear, fluid and messy. In the immediate post-Soviet period there was a momentous cultural shift between an official discourse that banned the values of individual autonomy and expression, to one that reverses this and externalises values and practices. Nowadays, the present revival of authoritarian orthodoxy under President Putin represents a vision of the future legitimated through backward looking nostalgia. Interestingly, there are echoes here of Stuart Hall's account of 'regressive modernisation' under Thatcher's authoritarian populism project in 1980s'Great Britain. What is distinctive about Hall's theorisation (in relation to Russia) is how authoritarianism was harnessed to create a similar affect: populism which is intended to mobilise people through the 'fears, the anxieties, the lost identities of a people (Hall, 1988:167). Over twenty years of amassing hundreds of prisoner and prison staff interviews what I have learned is that the penal actor in Russia today has a rich emotional vocabulary that she or her wants to share and which expresses these intertwining ideologies of the self 
and the loss of the collective. Take this previously unpublished interview I carried out with a prison officer in 2003:

"Well I see myself as a prison officer, I see myself as a worker, a man who comes to work, does his job and then goes home”.

Interviewer response: "I see. Do you think that these feelings are different from the late 1980s when you started out as a 'Soviet correctional officer'? Have your feelings changed at all?"

[ponders and looks downcast] "Yes and no. I was so proud of my job. I was a Soviet prison officer! I think about this more now than I did then...I feel...I don't know how to say it...I feel like a different man...I am supposed to do $X$ and $Y$ now...human rights...[waves hand dismissively]... that was different from before...I feel.... just feel...sadder now”.

By putting aside what I knew intuitively would have been an impractical distance between respondent and interviewee I respond to this despondent and sombre reflection with my own personal story of living in Odessa, Ukraine in 1996. I am working towards emotional connectedness here and, therefore, integrity. My field diary response as follows:

"I understand, I lived with a Russian couple of former engineers. The man was a bouncer now in a nightclub. He had lost his job in 1992 after 30 years as an army engineer. He was a big proud Russian man who drank too much and was depressed and alone most of the time. His wife had enough of the drinking and depression and just left! I was left alone with the bouncer for the rest of my time there but we started to bond and it became easier. He felt confused too."

In this interaction a high-trust environment was created because it opened up a long series of conversations between several prison guards and me about 'being Russian'. I came to know 'the field', not just of prisons but of Russian culture, from an epistemological participative position. Most of the prison officers I have interviewed in Russia would spend the time together with me talking me through 'life in Russia'. Often I was told, "Lets not talk about 
jails, let me tell you about me, my family, my life" 3. This is similar to Liebling's (2014) observation that we 'forget we are in prison and feel a form of friendship building' (Liebling, 2014: 484) except that in my case it is incumbent on me to forget I was in prison. Looking back at these spells of fieldwork between 1997 and 2007 there was a lot of posturing and parading of masculinities, familial roles and paternalism leading to over-immersion in the field. Alternative research strategies were pointless. And my success at fieldwork was contingent on 'just being me' which initially was frustrating and disorienting because I was there to research imprisonment not engage in self-scrutiny (which is, of course, Jewkes' (2014) well made point about how insights of self and insights of penal site meet and mesh). Smoothly-run research encounters would have failed to materialize unless I was, and continue to be, willing to leave prison-talk to one side. This is a further dimension to emotional commitment: suspending the academic self temporarily, with all the authority, labelling, suspicions, and interrupted interactions this would be bring and engage in acts of 'speaking of feelings and minds in common'. In order to understand the larger, relational word I inhabit in Russian prisons, and to have a chance of moving the research towards critical prison sociology, a spirit of companionship was fostered. In my field diary on another evening, I have the following recorded:

\section{"I found today's' interviews a bit upsetting and confusing. I feel I have some idea about how} the prison officers are struggling nowadays. I don't feel I spent much time today talking about imprisonment and I'm a bit panicked at this....not sure what data I have...but we did spend a long time just chatting about life in Russia. It was all quite sad really”.

My subjective experience was later shared by two colleagues who participated in a major research study into the relationship between women's imprisonment and geographical distance in Russia. On a pilot trip in 2006 published in Piacentini et. al (2009), myself and one other of our team were subjected to the ethnographic immobilization referred to earlier. The limits of empathy and emotional commitment were tested after a cultural ritual. This event acted not as a catalyst in my quest for more knowledge (which the diary entry above shows was a matter of some concern), but was instead an undesirable by-product of deep

\footnotetext{
${ }^{3}$ Similarly, see the work of Coretta Phillips and Rod Earle on ethnicity, identity and social relations in prisons published widely but specifically, here, I refer to Earle (2013) where the author argues that entangled relations between white ethnicities in prison and penal strategies of control can lead to messy and disturbed identities around loss, melancholy and the historical and colonial histories of race, which create certain penal affects.
} 
cultural immersion and I felt neutralized and angry afterwards as the following diary extract shows:

“Conference event went ok and we've set up the main fieldwork sites for next year. Had to attend a banquet. Loads of booze, and an amazing table of food. Then the music came on. All the men and senior prison staff were pretty drunk, dancing with the Russian men and women who were singing national songs and dressed in traditional Slavic costume. At first it was ok and familiar and then we were invited up. We politely refused several times but were persuaded to the point of feeling like we had no choice and had to join in the dance.... We were both so embarrassed and nervous. I felt sick and angry because the Russians moved away and we looked pretty stupid just dancing”.

At the time a feeling of being a half person was overwhelming: one day one is showing emotions of warmth, engagement and connection, leading to positive data collection experiences and the next day, feelings of anger, disgust and tension formed into negative judgments and a need for distance. As Katz (2004) has observed, moving from the emotion of connectedness to the emotion of disembodiment and detachment can create psychological chaos in researchers as they try to consider how a state of being bears upon the researcher's obligation to be reflexive about the position from which we choose to speak. The "reality" was that many data collection experiences I have gathered - and will accumulate again in my next study - led me to pursue a particular path of epistemological inquiry, which is asking an empirical question about culture's bearing on penal developments ${ }^{4}$. Emotional identification with the field site revealed to me how the prison is a key arena of culture and ideology: 'penal practices' argues Garland 'are shaped by the symbolic grammar of cultural forms as well as by the more instrumental dynamics of social action, so that, in analysing punishment, we should look for patterns of cultural expression as well as logics of material interest or social control' (Garland, 1990: 199). Garland was examining Western penal development and despite the paucity of scholarship on the cultural meaning of punishment in non-Western jurisdictions, Garland shows how institutional language and values come to be formed from outside-to-inside in non-Western penal cultures. According to Garland (1990) and Smith (2008) penality's role in the creation of culture is, therefore, to communicate meaning and is both its cause and its effect. Hence, Russia's cultural penal paradox is this: as the Soviet era

\footnotetext{
${ }^{4}$ Empirical scholarship looking at culture's effects on penality has yet to be rigorously pursued.
} 
is becoming more and more distant, remaining there, still, are signifiers of social/institutional life of prisons, from the architectural design of communal living, which carries forward Gulag prison design, to feminine-preserving beauty contests and the organised criminal gangs who practice a form of prisoner self-governance.

\section{Integrity and emotional commitment}

When transitioning into a prison site, the fieldworker makes multiple commitments to others on site. This has led to a very noticeable and recurring research dilemma of demonstrating integrity and accountability to a range of penal actors. My response to these dilemmas is to bring us back to what I think must be the central proposition for ethnographers and this is: "what does an ethnographer hope to find in the ethnogrpahic connection"? Jensen, (2009), discussing integrity in business studies scholarship, writes:

"Integrity [in our model] is a purely positive phenomenon. It has nothing to do with good vs. bad, right vs. wrong behaviour. Like the law of gravity the law of integrity just is, and if you violate the law of integrity....you get hurt just as if you try to violate the law of gravity with no safety device" (Jensen, 2009:15).

In summarising my approach to prison ethnography, I would argue that the following 4 themes are useful as reflexive guidance questions for data collection, analysis and establishing boundaries:

- What I say - stating explicitly what I set out to achieve.

- What I know - doing research as I know it is meant to be done. Who do I hold myself out to be?

- What is expected of me - even when not explicitly expressed, what do others expect me 'to do'?

- What I stand for - fundamental to who I am and why I am there.

It is what is said by me and what is said by my actions that are the keys to my ethnographic approach, and at the centre of this is integrity. Integrity is the cornerstone of all research, yet it is not explored in great depth in ethnographic research and is taken to be as a given. Integrity is as much about virtue, as it is about wholeness and completeness. It is about 'honouring your word', which is the same as saying 'I will honour the standards for research 
that I set'. It cannot, therefore, be described as research instrument. In honouring standards set, appropriate parameters are laid down and it is these parameters that make them effective tools for understanding the human behaviour that we study. Yet, integrity is also the consistency of actions, the clarity of thoughts and deeds and the truthfulness of values presented and developed. To have integrity, therefore, is to aim for wholeness, positivity and to produce workable frameworks that enhance performance in the research field. And so too is it the case with accountability that without it, the protocols we follow and the quality of the measures we put into place to ensure we protect our participants' confidentiality, will fall apart. Without integrity, there is no accountability. The following two diary entries from 2007 reveals that despite the reality of feeling uncomfortable in the field, emotional identification with the external-to-prison context was vital to create effective integrity and robust research positionality:

"Set off to a beauty pageant alone from my prison digs through snow to the recreation hall. It was dark, cold and quiet. Overwhelming feelings of living in a jail, really cold, Russia, snow. Walked into find a sea of faces, dark prison clothes, shaved heads and silence. Couldn't stop thinking of prison memoirs. Loads of guards with rifles and then me and something like 300 male prisoners. Tried to smile at prisoners. They stared into space and when music came on and dancers appeared, the stony faces stayed and we all clapped at the same time. Had loads of questions but decided best to just clap along”. (1997).

"Today was my third beauty pageant and talent show. All three of us went. Here we go again. Just a few guards this time and no prisoners. The young woman prisoner's ballet tutu fell to her feet. It was a moment of embarrassment for her and we just sat there...staring into space...she recovered well. We talked about it afterwards and we had different views but I just felt cynical even though we were told the women prisoners loved putting on the show' (2007).

These two excerpts reveal how the impact of how I am for myself, and the impact on how I am for others, was determined by the nature of what I stand for. Indeed to advance knowledge relies on trust and honesty that must be established well in advance of entering the field and always maintained whilst there. My story is therefore an ethnography of discovery conducted well in advance, even years before, the site is entered. Yet, prison ethnography is more than a journey of discovery. It is also a process of theoretical validation. The get-close 
approach to prison ethnography demands often contradictory tasks where one has to develop a 'feel' for the prison through rapport building and management of multiple stand-points and interests. As Phillips and Earle (2010) note, producing knowledge from situated experiences creates not only nuanced knowledge of the realities of those under investigation, but also, that knowledge represents social structures and multiplicities of experience that are intersectional and reflexive. By implicating oneself in the subject of choice, getting inside the field and then in the writing up, the researcher, as I have said elsewhere, is writing themselves into the story and this can provoke a researcher into settling on a surer conceptual framework for the world they are observing (see Piacentini, 2007). A corollary of understanding prison fieldwork in this way is the disparate views that can be held between researchers coming from different disciplines into a shared field site (as was the case in the different interpretations of the beauty pageant of 2007).

\section{Conclusion}

Having integrity, honouring your word whilst articulating the conflicts of the social world and its consequences, is riddled with problems, especially where the political and social environment is as challenging and turbulent as it is in Russia. For prison ethnographers, the prison site is highly complex anyway because it is subject to a particular form of representation (public/political/cultural/contingent/emotional), which means that the balance between integrity and accountability is more acutely felt as the choice of site is pointedly challenged (I refer here to the often asked question of 'why prison research'?). A total and a totalising institution, the prison is both a closed space and a porous place where ideologies, practices and pains ebb and flow, where experiences are shared, and stories with a beginning, a middle and an end unfold (sentences are completed, lights are turned off and on, timetables are set, doors are locked and opened, guards return home). Moreover, entries and exits are multiple and contingent. Prisoners also have to commute this emotional mine-field. Preconceptions about penal punishment are disrupted as soon as you walk into a prison because it is also a place where things are not said, truths are not admitted to, feelings are not shared, and realties are not exposed.

Penetrating prison experiences creates immediate ethnographic burdens of seeing and then writing. It is this very essential nature of the penal sphere that demands of us openness to change, and willingness to see everything. Going back to a point I made earlier about what 
the ethnographer hopes to find in the field, ethnography is both the story, and the webs of meaning (Geertz, 1973) underlying 'the story'. Prison ethnographies, then, can never be fully fledged or completely whole unless we look at the totality of seeing that exists between people and the environment, all wrapped not very neatly around a highly regulated space. I also outlined how prison researchers often describe how their psycho-social defences are challenged. To be sure, what is demanded of me (from my participants) is a visible ethnocultural field inquiry. I have learned (accepted?), persuaded by my gatekeepers and my participants, that to silence the inquisitive voice and not interrogate 'life stories' would silence my participants' voices, would lead my participants to question my integrity and potentially shut down the research process. Thus the cost, both personal and to research, is always potentially high when an ethnographer does not have integrity.

In summary, if integrity is the formal relation one has to oneself and standing for something, what are the effects of having integrity during prison research? I have in the past had an almost unimpaired access to opportunities to get as close as I could, and as close as I desired, to the field. This has now changed and my integrity, whilst creating hiddenness through acceptance and 'being one of them', nowadays, is subject to dispute not because I am not honouring myself but because the research environment is highly politicised. As a postscript then, I would like to raise a hitherto under-explored prison sociological question on the theme of transitioning out, temporarily, from field site to policy critique. The central question I ask below is: what is the place of emotions in policy critique? Where do emotions go?

\section{Postscript: transitioning out, ethnography or policy critique?}

Forsythe (1999) describes ethnography as invisible work, adding that when a researcher is 'just chatting' this is no more than when a doctor is 'just talking to patients'. In other words, a competent prison researcher will take people's views and feelings as data, not as results. My intention to this point was to show how the analytical expertise deployed in prison ethnography is a form of 'cognitive walk-through', which can be understood as an experiential moment, a gathering of voices, a continual questioning of 'for whom and for what' and a heightened awareness of flows of meanings and ruptures in relationships. Whilst an approach of ethno-cultural connectedness is essential in overcoming over-generalisation and creating theoretical rigour, minimising over-generalisation and heightening theoretical 
rigour are also tenets of good policy critique and cannot be said to be the preserve of field research. As mentioned in the introduction, prisons exist in space and time but they also exist in policy and law, where a critique may reveal a heightening sense of how law and policy are mobilized into penal spaces. A heightened awareness of the text, of the discourse and of how penal spaces come to be composed of law and policy gives promise of a diagnosis of penal life that may not be too different in form from the ethnographer's perspective. As I embark on a new Russian prison project that takes me towards my twentieth year of prison sociology on this subject, I face a challenge: in the short-term I will not be following the path of prison ethnography - that comes later - so where do I put my emotions when analysing Russian penal policy? Do emotions have a place in policy critique and is there a conflict of coverage between being there and not being there?

The most obvious place where emotional responses can arouse emotional reactions to imprisonment is the international penal reform movement. If putting more people in jail, and for longer, tests our conventional wisdom of what a prison sentence means, in penal reform discourse this conventional wisdom is emboldened with the narratives of rights violations, degrading treatment and penal atrocity. Penal reform as a movement, and as an ideology, provides the prison sociologist and citizen alike with a rich narrative of 'penal detail' and a place to put their emotional reactions to confinement. The multi-faceted nature of penal reform strikes at the roots of penal legitimacy. That is, is the detention of citizens lawful, justified and humane? Penal reform critique is complex not least due to the question of how to enhance the legitimacy of critiquing systems of punishment and at the same time maintaining proximity to the audiences targeted. For our purposes here, this textual reading of penal pain has proved to be effective in mobilising emotional and psychological reactions. This is because of the highly valuable visual messages and textual stories that outline how imprisonment is a painful retribution that strikes a highly sensitive chord both in how the just measure of pain is turned into (sometimes inexplicable) sentencing policy (see Christie, 2000) and in how in prisons, in every context, are the so-called carriers of danger transferred into spaces from which they cannot escape (Bauman, 2000). Is it not, therefore, the case that the prison becomes a site of contested emotionality because we respond to stories of incarceration in a myriad of ways but all pointing uni-directionally towards the prisoner? For example, amongst numerous accounts of painful penal experiences, we often read of the regime that executes children, the death row inmate who was in terrible pain at the point of death, the woman who is stoned to death for 'adultery', or the suicide of vulnerable adult men 
for whom 'risk assessment' has failed. These above examples take the reader and the viewer towards connecting to prisoners, to question the legal limits of punishment and to see and feel its ubiquitous presence. And yet, prisons' place within society and crime control has become so non-disrupted that we tolerate their normality whilst not tolerating the malevolence of the persons held within (the contained).

Reading penal reform campaigns can induce what Bauman calls 'emotional/attitudinal unity' (Bauman, 2000: 35) because the linguistic temperament of penal reform campaigns forces our eye to view penal experiences as truly atrocious, and we must respond. Thus, through exposing the illegitimacy of punishment forms, the legitimacy of penal reform processes is secured. One important matter that is excluded from the penal reform movement is the rendering of the prison itself as a socially constructed, normative world. A prison sentence is one that requires cultural, political and legal justification from the outside; a symbol not only of society's lost trust in legal obedience, but also, society's justification for policies aimed at prisoners. It is the longing for order more broadly defined that ensures a prison's endurance because, as both Foucault (1977) and Bauman (2000) note, the prison is an expression of society's quest for order and in a well-ordered society, the norm of order tells people how to be behave. It could therefore be argued that aside from penal reform campaigns the desire for a more general social order offers an excuse for "whatever actions follow that sentiment' (Bauman, 2000: 23). In other words, the more we meet crimes with imprisonment, the more banal and emotionless imprisonment becomes. The question for sociologists of the prison then is whether we can we merge the emotions of ethnography with the emotions of policy critique in settings where prisons are regularised, predictable and uniform institutions of norm regulation. There are many ways to conduct prison research but if we take the researcher's body away from the site, we face the dangerous situation of training the critical eye only on prisoners and not on the site itself as 'the stage of human suffering' (Armstrong, forthcoming: 1). This is due to two things. First there appears to be a gap between critical expert knowledges and penal policy reductionism (despite expertise playing a bigger role in penal policy development). Second, is what Armstrong (forthcoming) argues is the process of co-opting penal critique into penal management cultures that deemotionalise the deleterious effects of incarceration. In effect what Armstrong is saying is that we have become expert in the 'dealing with prisoners' part but ineffective and nullified about the part dealing with the prison's wider social consequence. We have then become 
'imprisoned by prison discourse' (Armstrong, forthcoming: 4), which is remarkable since prisons are politically cast and policy relevant (Katz, 2004).

And so there appears to be a growing gap between the high quality prison ethnographic research outlined in this volume and away-from-prison critical, perhaps even emotional, responses to problematising the prison. This raises the important question: where is it safe to talk about emotions and think reflexively about confinement? As important as joining penal reform campaigns are in creating spaces for emotions to run freely, it is only part of a deeper change in conception, discourse and response to penal policy where we see emotions 'transitioning out' because in policy critique, the prison is understood through the bodies contained and not the through law and order rhetoric or populist punitiveness.

The thriving academic scholarship on prison ethnography speaks directly and powerfully to researcher accountability and non-estrangement. The rich variability of experiences reminds us also that doing prison research is akin to experiencing academic vertigo: not having integrity means being showing variously as inconsistent, unfocused, scattered, unreliable, undependable, unpredictable, and generally unaccountable. For a stark fact stands out: prison research pushes to the frontline Becker's oft-quoted statement: whose side are we on? (Becker 1967). In constantly asking this question of ourselves the moral and emotional density of meaning becomes less of a personal experience and more one that is theoretically embedded. Moreover, it is also entirely sensible, indeed it is necessary, to ask 'whose side are we on' when conducting non-field site prison critique, not least because of the inevitability of incarceration. Whilst societal turbulence, the like of which I am currently witnessing in Russia is impacting on how and when I return to the research site, I would suggest that the taken-for-grantedness of how the prison institution itself is a site of multiple, complex meanings that render the contained invisible must always be questioned. Thus, integrity is about honouring ones word, not keeping ones word. In this sense, integrity is 'privately optimal' (Jensen et.al 2009:29), meaning, I can create meaningful, critical knowledge and have integrity even where the other is negative towards me and, moreover, when I am not 'there'. 


\section{Acknowledgements}

This article draws upon some work from the study: Women in the Russian Penal System: The role of distance in the theory and practice of imprisonment in late Soviet and post-Soviet Russia funded by the Economic and Social Research Council, RES-062-23-0026, 2006-2010. It also introduces a new study funded by the Leverhulme Trust, commencing 2015 titled, $A$ Sociology of Rights Consciousness amongst Russian Prisoners.

\section{References}

Armstrong, S. (forthcoming) Prison as Stage and Actor.

Becker, H. ((1967) 'Whose Side Are We On'?’ Social Problems, 14/3: 234-47

Bauman, Z. (2000) 'The Social uses of Law and Order', in D. Garland, and R. Sparks, (eds) Criminology and Social Theory. Clarendon Studies in Criminology: Oxford University Press

Clemmer, D. (1958 ed) The Prison Community. Rinehart Publishing

Jewkes, Y. (2014) 'An Introduction to "Doing Prison Research Differently", Qualitative Inquiry, Vol. 20 (4): 387

Liebling, A. (20104) 'Postscript: Integrity and Emotion in Prison Research', Qualitative Inquiry, Vol. 20 (4): 481

Clifford, J. (1983) 'On Ethnographic Authority', Representations, No. 2 (Spring, 1983), pp. $118-14$

Coffey, A. (2000) The Ethnographic Self: Fieldwork and the Representation of Identity. Sage: UK

Cohen, S. and Taylor, L. (1972) Psychological survival: The experience of long-term imprisonment. Harmondsworth UK: Penguin

Crewe, B. (2014a) 'Not looking Hard Enough: Masculinity, Emotion, and prison Research', Qualitative Inquiry, 201420 (4)

Crewe, (2014b) 'The Emotional Geography of Prison Life', Theoretical Criminology, May $2014(18(2)$ 
Davis, F. (1973) 'The Martian and the Convert' Ontological Polarities in Social Research, Urban Life and Culture, Vol. 2, pp. 333-343

Earle, R. (2013) 'Inside white: racism, ethnicity and social relations in English prisons', in Phillips, C. and Webster, C. (eds) New Directions in Race, Ethnicity and Crime. Abingdon: Routledge, pp. 160-177

Forsythe, D. E. (1999) “"It's Just a Matter of Common Sense” Ethnography as Invisible Work', Computer Supported Cooperative Work Vol 8, 127-145, 1999

Garland, D. (1990) Punishment and Modern Society: A Study in Social Theory. Oxford University Press

Garland, D. (2001) The Culture of Control: Crime and Social Order in Contemporary Society. The University of Chicago press

Garland, D., Sparks, R. (2000) 'Criminology, Social Theory and the Challenge of Our Times', in D. Garland, and R. Sparks, (eds) Criminology and Social Theory. Clarendon Studies in Criminology: Oxford University Press

Geertz, C. (1973) The Interpretation of Culture. NY: Basic books.

Goffman, E. (1958) Asylums: Essays on the social situation of mental patients and other inmates.

Feeley, M. M., and Simon, J, (1992) 'The New Penology: Notes on the Emerging Strategy of Corrections and Its Implications', 30 Criminology 449

Foucault, M. (1980) Power/Knowledge: Selected Interviews and Other Writings, 1972-1977. Vintage; 1st American Ed edition

Hall, S. (1988). The Hard Road to Renewal: Thatcherism and the Crisis of the Left. London: Verso.

Irwin, J. (1987) 'Reflections on Ethnography', Journal of Contemporary Ethnography, 16: $41-48$

Jensen, M. C. (2009) 'Integrity: Without it Nothing Works', Harvard Business School NOM Unit Working Paper No. 10-042

Jewkes, Y. (2014) 'An Introduction to "Doing Prison Research Differently", Qualitative Inquiry, Vol. 20 (4): 387 
Katz, J. (2004) 'On the Rhetoric and Politics of Ethnographic Methodology', The Annals of the American Academy of Political and Social Science, September 2004 vol. 595 no. 1 280-308

Kharkhordin, O. (1999) The Collective and the Individual in Russia: A Study of Pratices. University of California Press, Berkeley.

Liebling, A. (20104) 'Postscript: Integrity and Emotion in Prison Researc', Qualitative Inquiry, Vol. 20 (4): 481

Pallot, J. and Piacentini. L. (2012) Gender, Geography and Punishment: The Experience of Women in Carceral Russia. Oxford University Press

Phillips, C. and Earle, R. (2010) 'Reading Difference Differently? : Identity, Epistemology and Prison Ethnography', The British Journal of Criminology, Vol. 50, Issue 2, pp. $360-378,2010$

Piacentini, L. (2004) Surviving Russian Prisons: Punishment, Politics and Economy in Transition. Willan

Piacentini, L. (2007) 'Handle with Care: New and Established Methodologies in Prison Research', in Y. Jewkes (ed). The Handbook on Prisons. Willan

Piacentini, L., Pallot, J. and Moran, D. (2009) 'Welcome to 'Malaya Rodina' (Little Homeland): Gender, Control and Penal Order in a Russian prison, The Journal of Socio-Legal Studies

Pratt, J., Brown, D., Brown, M., Hallsworth, S. and Morrison, W. (2005) The New Punitiveness: trends, theories, perspectives. Willan Cullompton

Rabinow, P. (1988) 'Beyond Ethnography: Anthropology as Nominalism', Cultural Anthropology, Vol. 3, No. 4 (Nov, 1988), pp. 355-364

Rowe, A. (2014) 'Situating the Self in Prison Research: Power, Identity, and Epistemology, Qualitative Inquiry, 2014 20(4)

Smith, P. (2008) Punishment and Culture University of Chicago Press

Sykes, G. (1958) The society of captives: A study of a maximum security prison. Princeton, NJ: Princeton University Press

Wacquant, L. (2002) 'The curious eclipse of prison ethnography in the age of mass incarceration', Ethnography, 3 (4), 371-398 


\section{Chapter outline}

This chapter outlines experiences of, and findings from, prison ethnography in Russia over a twenty year period. The chapter draws from new data discovered, and new theoretical conceptual frameworks developed, when navigating this exceptional and complex penal space. The chapter also offers a postscript to prison ethnography that seeks to be of scholarly usefulness outside of the Russian jurisdiction. That is, the chapter asks what are the effects of prison research on the self when the scholarship undertaken moves from field-site to policysite? A second question raised is whether in penal policy scholarship 'emotions' become invisible and whether there is a need for emotional safety and emotional connectendess out of the prison field.

\section{Chapter summary}

Russia continues to be a place of high punishment that is immobilised as a site for research due to the effects of the vast penal monolith of the Soviet period and the current political climate. The effects on the researcher are multiple, contingent and messy. Prison ethnographers can easily move between ethnographic worlds of mobilisation and immobilisation. The chapter calls for ethno-cultural proximity to build theoretically rigorous knowledges on incarceration. The chapter also highlights how integrity, the cornerstone of all research, becomes a contested value in penal environments due largely to the complex, and unique hidden-ness of penal contexts, their socio-spatial regulation, the wider political and cultural responses to crime and, importantly, the focussed attention on 'prisoners as problems'. As prisons have become normalised institutional forms, this has led to a weakened emotional reaction to policy critique, broadly defined. The chapter asks, therefore, whether it is possible, indeed desirable, to harness the emotional reactions to incarceration gathered from the thick descriptions that ethnography delivers, and transpose these onto penal policy critique.

\section{2-3 suggestions for further reading}

1. Alford, F. C. (2000) 'What would matter if everything Foucault said about prison were wrong? Discipline and Punish after twenty years', Theory and Society, 29: 125146

2. Heinlein, S. (2013) Among Murders: Life After Prison. University of California Press

3. Smith, C. (2009) The Prison and the American Imagination. Yale University Press, New Haven \& London 